\title{
Protée
}

\section{Michael Slobodian : Photographier la danse}

\section{Jacques Bachand}

Volume 29, numéro 2, 2001

Danse et altérité

URI : https://id.erudit.org/iderudit/030625ar

DOI : https://doi.org/10.7202/030625ar

Aller au sommaire du numéro

Éditeur(s)

Département des arts et lettres - Université du Québec à Chicoutimi

ISSN

0300-3523 (imprimé)

1708-2307 (numérique)

Découvrir la revue

Citer cet article

Bachand, J. (2001). Michael Slobodian : Photographier la danse. Protée, 29(2),

50-58. https://doi.org/10.7202/030625ar d'utilisation que vous pouvez consulter en ligne.

https://apropos.erudit.org/fr/usagers/politique-dutilisation/ 

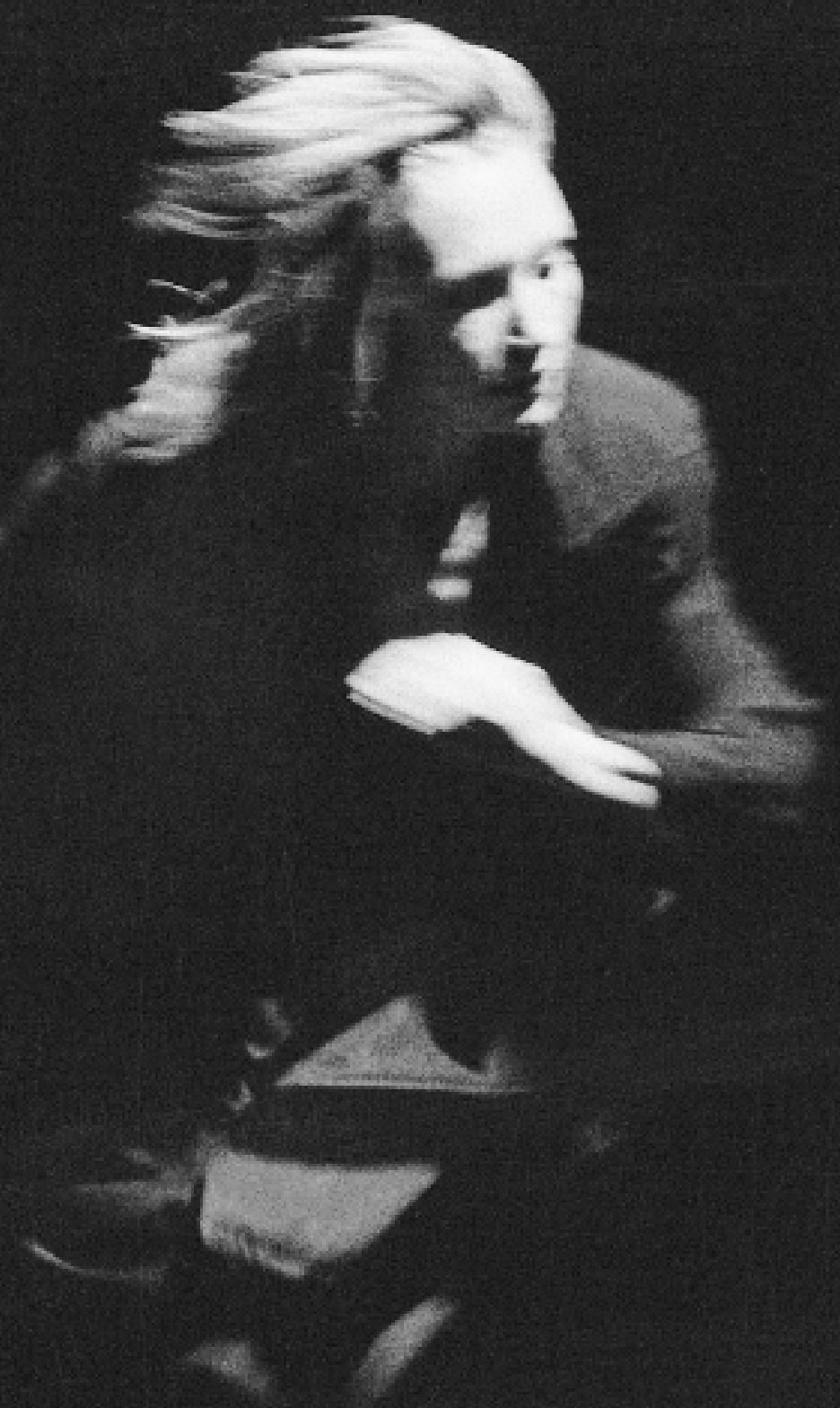

\section{MICHAEL SLO BO DIAN}

Photographe de danse depuis plus de vingt ans pour des compagnies de danse d'ici et d'ailleurs, Michael Slobodian veut montrer plus que le travail du photographe. Fasciné par la manière dont les danseurs utilisent le corps, Michael Slobodian, avec la photographie, rend compte de la poétique du danseur, de sa force et de sa grâce. 


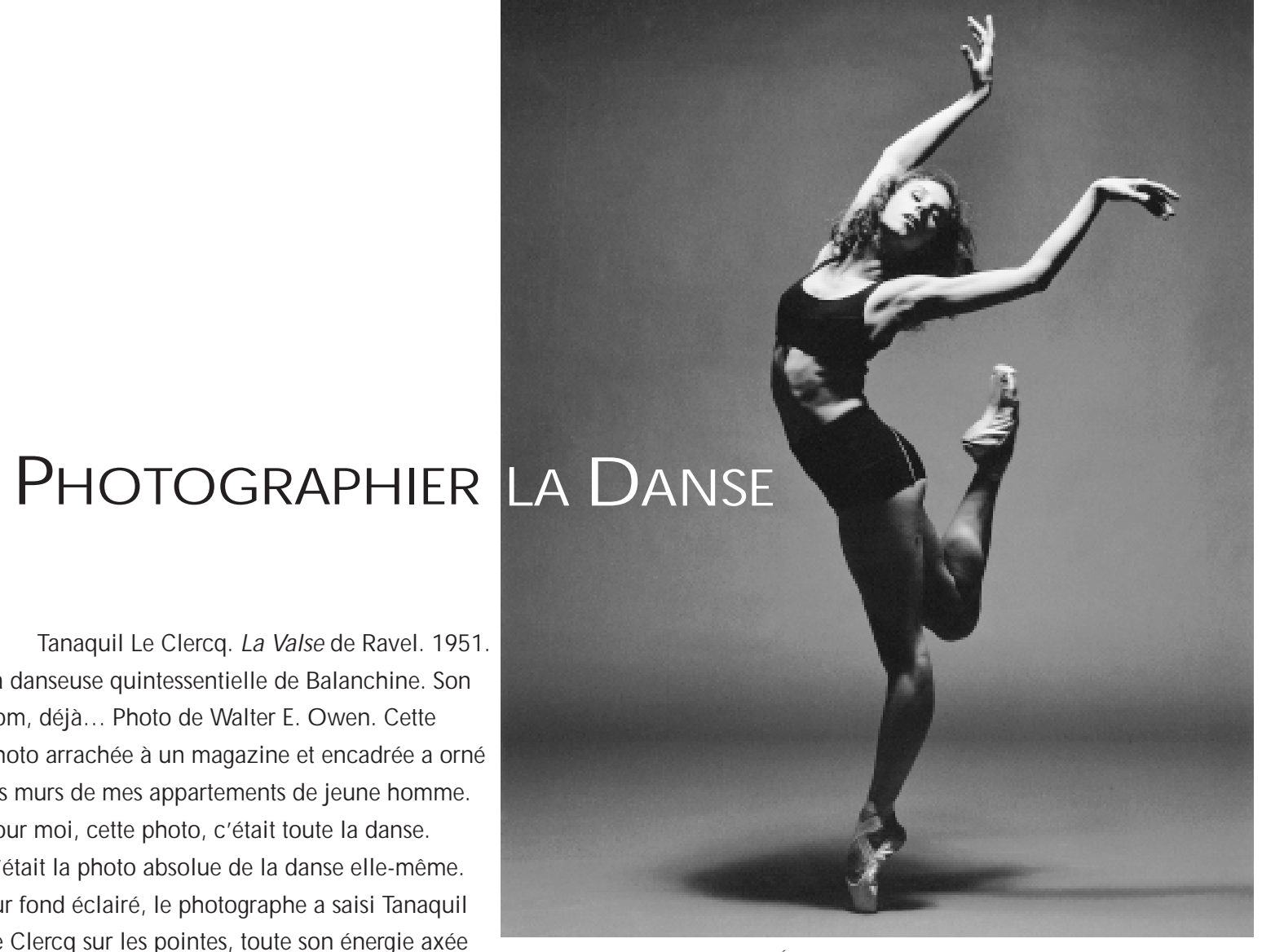

Le Clercq sur les pointes, toute son énergie axée sur sa colonne vertébrale en parfaite verticalité, les

Michael Slobodian, Étude personnelle. Interprète : Naomi Stikeman. mains voletant au-dessus de sa tête, le bras gauche bien droit, le droit à $45^{\circ}$, en sissonne, en déboulé ou en temps de flèche, on ne sait trop, mais l'éclairage donne à admirer des volants, que dis-je? une voilure virevoltante coupée en son milieu par la longue robe foncée (la photo est en noir et blanc) profondément échancrée sur la poitrine de Tanaquil Le Clercq, visage triomphant.

En 1982, je suis rentré de New York avec une grande affiche d'un spectacle de l'Alvin Ailey que j'étais allé voir au N ew York City Center. Adieu Tanaquil! La photo de danse avait changé, et la danse d'abord. Sur fond noir, le lumineux danseur Keith McDaniel, jambes pliées, pieds presque croisés, le bras gauche tendu à l'horizontale, le droit à la verticale, vole littéralement au-dessus du photographe Jack Vartoogian. Spectrum. Musculature éclatante d'énergie. Athlétique acrobate. Jeunesse en plein vol. L'envol est la vie, disait la Pavlova.

La photo de danse est toute une entreprise. II faut voir d'où l'on part. Q uand Nadar fait ses premières photos de danse, la photo n'a pas encore résolu toutes ses questions de chimie et exige une pause d'une bonne demi-minute. Pas évident de saisir une échappée de Carlotta Grisi dans Giselle ou les entrechats de Marie Taglioni dans Pas de quatre! Le photographe d'aujourd'hui, avec son appareil photo à un millième de seconde, sait-il pour autant saisir mieux l'essentiel de la danse: la continuité fluide du mouvement expressif? Par ailleurs, la photo de danse se développe en même temps, à partir de 1850, que la photo de mode. Lola Montès chez Dolce \& Gabbana. Ces beautés laissent des traces. Et puis, imaginez encore que la Taglioni avait révolutionné le ballet en dansant toute La Sylphide sur les pointes et vêtue de ce nouveau juponnage appelé tutu. Comment, après cela, dire la danse en photo sans les pointes et sans le tutu?

Passé les theatrical photographs de Broadway, le zoopraxiscope du major Muybridge va permettre l'émergence du premier grand photographe de danse, le baron Adolf de M eyer. C'est lui qui saisira la légende de L'A près-midi du génial faune $\mathrm{N}$ ijinski. Avec Arnold G enthe, le photographe d'Isadora Duncan, il imposera la norme, le style, la manière de la photo de danse, avant que le cinéma s'en mêle. Busby Berkeley: 54 films, avec Gene Kelley entre autres, marque le genre, jusqu'à la formidable image publicitaire de M artha Swope: John Travolta, Saturday Night Fever, 1977. Swope avait étudié la danse à la School of American Ballet.

La leçon du baron (N oureïev reconnaissait s'être inspiré du portfolio du baron pour son interprétation de L'Aprèsmidi avec le Joffrey Ballet) est que l'entreprise de la photo de danse ne peut réussir que si le photographe arrive à saisir 


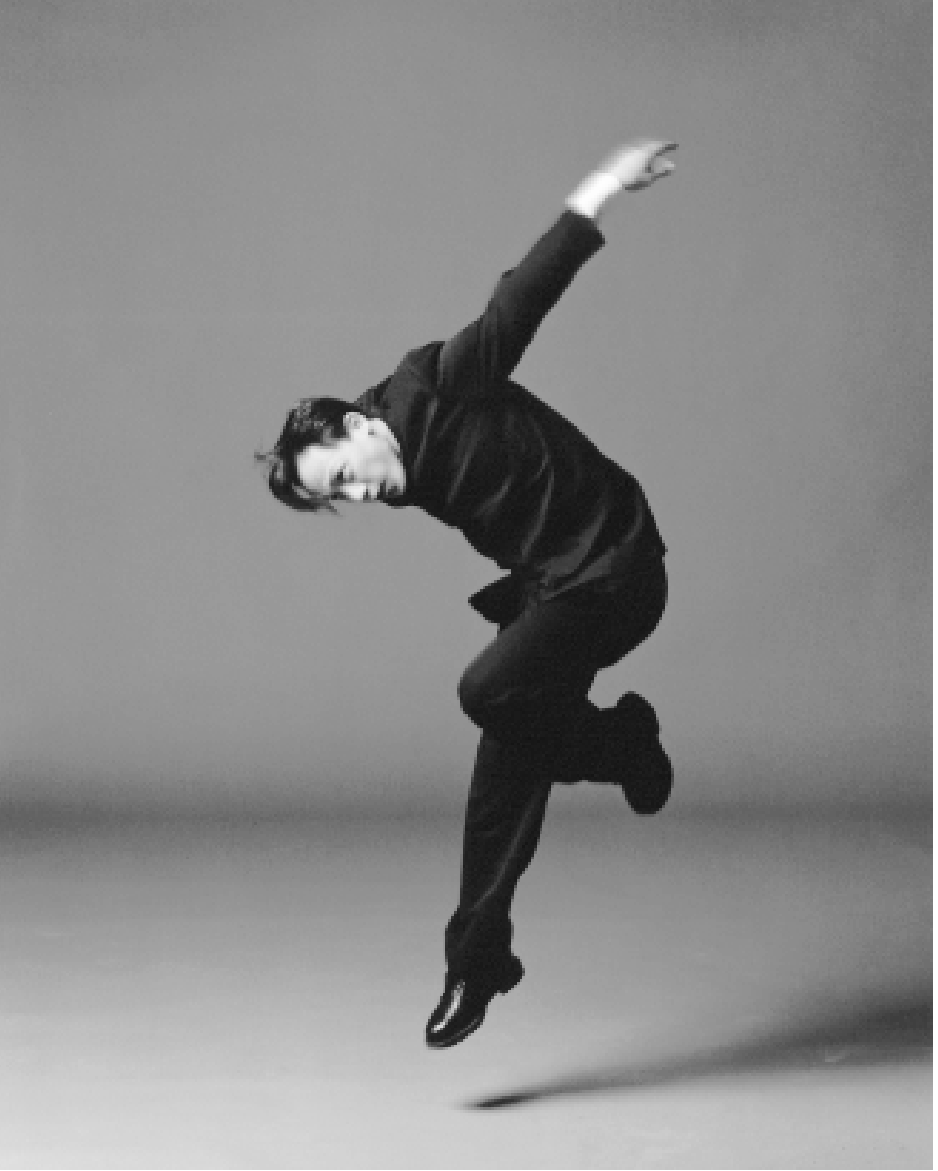

Michael Slobodian, Étude personnelle. Interprète: Rick Tjia. l'essentiel du langage chorégraphique, signifiant et signifié: un corps qui répercute en mouvements les états et les intensités de l'âme, de l'idée et probablement du corps lui-même. Ces bras pliés ou tendus, ces épaules relevées ou abaissées, ce torse incurvé, ces cuisses tendues, écartées devant, derrière ou de côté, ces pieds pointés, ces métatarses tordus, cette jambe de terre qui porte le corps et cette jambe libre qui fait le pas, ces impulsions, élévations et réceptions, cet étirement maximal du triceps sural et du quadriceps crural ne disent rien si le photographe ne saisit la dynamique et l'expressivité du corps en mouvement rotatif, en grand saut ou en cabriole, s'il ne sait capter l'énergie d'un jeté, la grâce d'une arabesque, la détente d'un adage. Les mouvements, les positions de base, les enchaînements, tous ces flic flac et faillis sont autant de défis pour le photographe soucieux de faire signifier, dans un instantané, la plasticité de ces éléments du langage chorégraphique.

La danse se nourrit du mouvement lui-même, dit M erce Cunningham. Voilà indéniablement ce que le photographe doit donner à voir, et en cela même le plaisir et le sens du mouvement. Cela se fait en mettant le corps en valeur, certes, comme le veut Bill T. Jones, mais en y saisissant l'énergie d'une humeur, le dynamisme d'une idée, l'expressivité immanente d'un mouvement. En donnant à voir la physicalité qui attise, la corporéité comme construction mentale, le photographe expose le sens de la danse comme mouvements propres générant des formes autonomes. Ici, les pieds ne sont pas pour marcher, mais pour léviter.

La photographie de danse doit d'abord dire la danse; et le corps dansant énonce. Son sujet n'est pas l'acrobatie, mais la polarisation expressive du cinétique et de l'inertiel, un instantané pris sur une transition, comme dit Bergson.

Il est sans doute relativement facile pour le photographe de capter la performance athlétique, la beauté du biceps ou du mollet tendus. On se souviendra que le mollet de la danseuse symbolise la vulgarité des effets de discours, pourtant incontournables en écriture (Barthes), mais c'est un corps iconique que met en apesanteur le mollet de la danseuse.

Le photographe de danse qui doit montrer la course affolée des danseuses de Pina Bausch dans Le Sacre du printemps, les embrassades passionnées dans Le Parc d'Angelin Preljocaj, l'image de la jouissance dans la violence du monde dans Les Couleurs de Maduraï de Carolyn Carlson, la piaffante angoisse de Joe et la solitude suffocante dans L'Exil, I'oubli de JeanPierre Perreault, est devant une entreprise où rien n'est donné. Il y a bien, certes, la mort du cygne, le cliché absolu du ballet et cliché au carré du photographe, solo pourtant composé en moins d'une heure par la Pavlova, sous la direction de Fokine, pour, veut la légende, remplacer un duo qu'elle devait danser le soir même avec Nijinski, tombé malade. Pourtant, la mort du cygne n'est pas qu'une promenade de pas de bourrée sur les pointes, coupée par des arabesques en allongée et équilibrée par les bras ouverts qui ondulent; c'est aussi cette blanche agonie, dit Mallarmé.

Dans Degas Danse Dessin, Valery écrit: «ll y a une immense différence entre voir une chose sans le crayon dans la main, et la voir en la dessinant. [... ] II faut ici vouloir pour voir et cette vue voulue a le dessin pour fin et pour moyen à la fois». Comme D egas dessine, Michael Slobodian photographie la danse. 


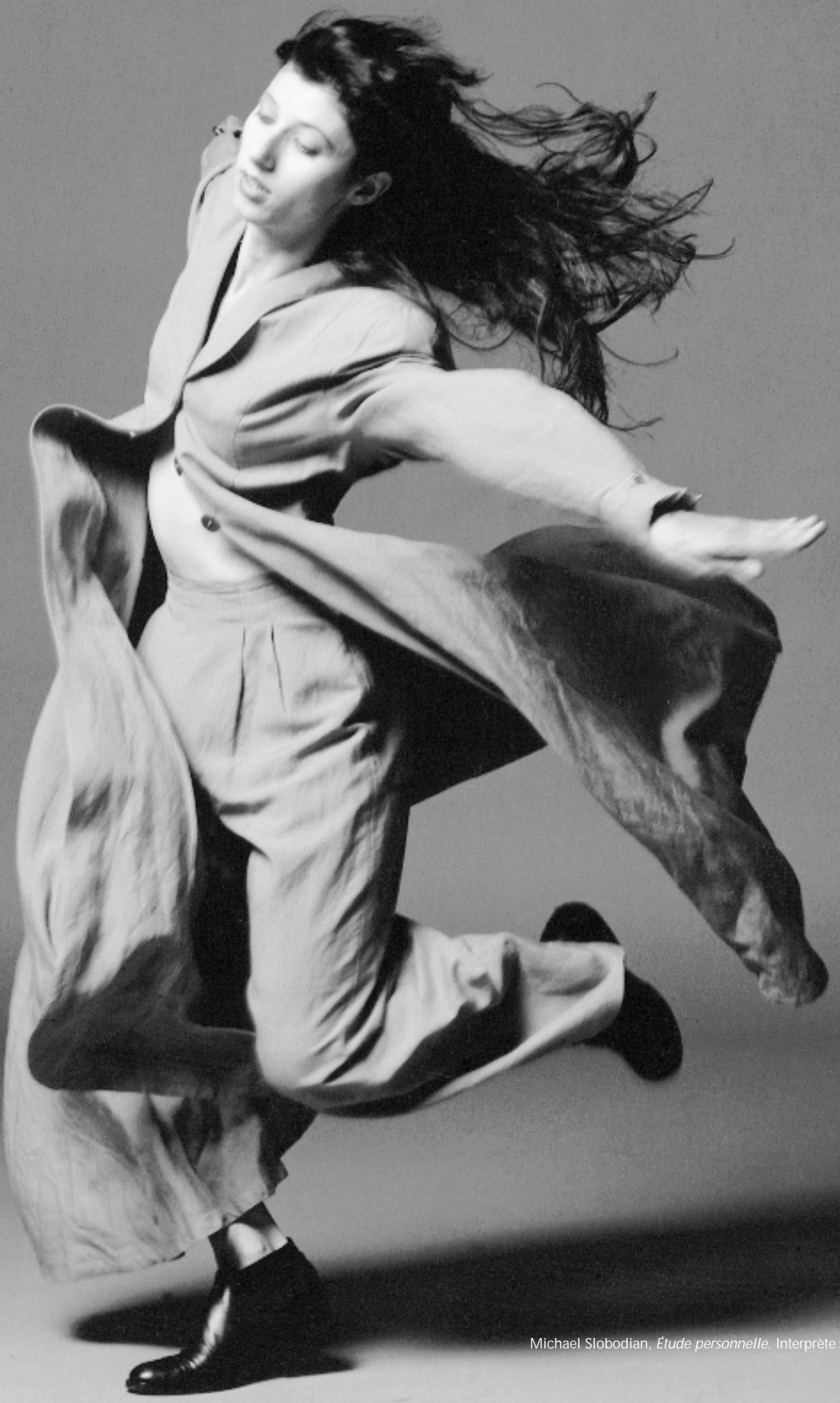




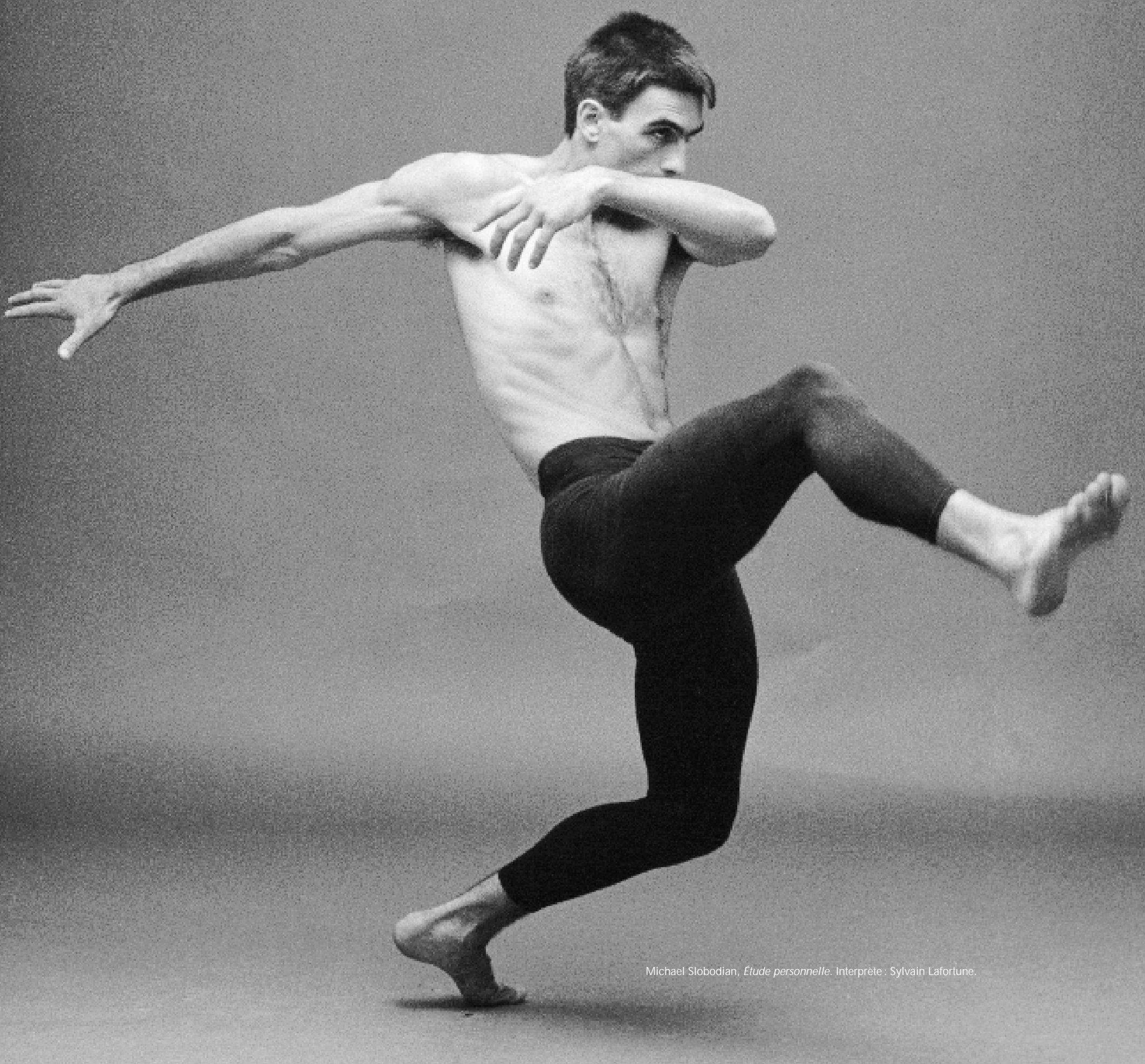




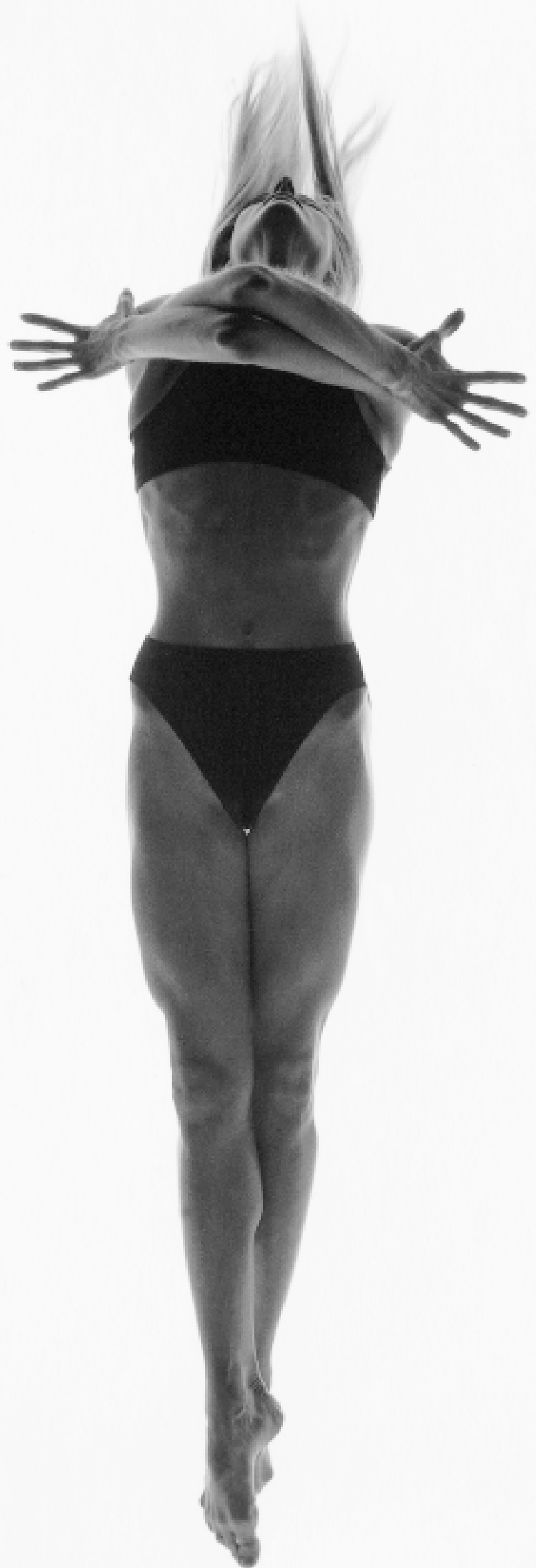

Michael Slobodian, Étude personnelle. Interprète: Catherine. 


$$
t
$$




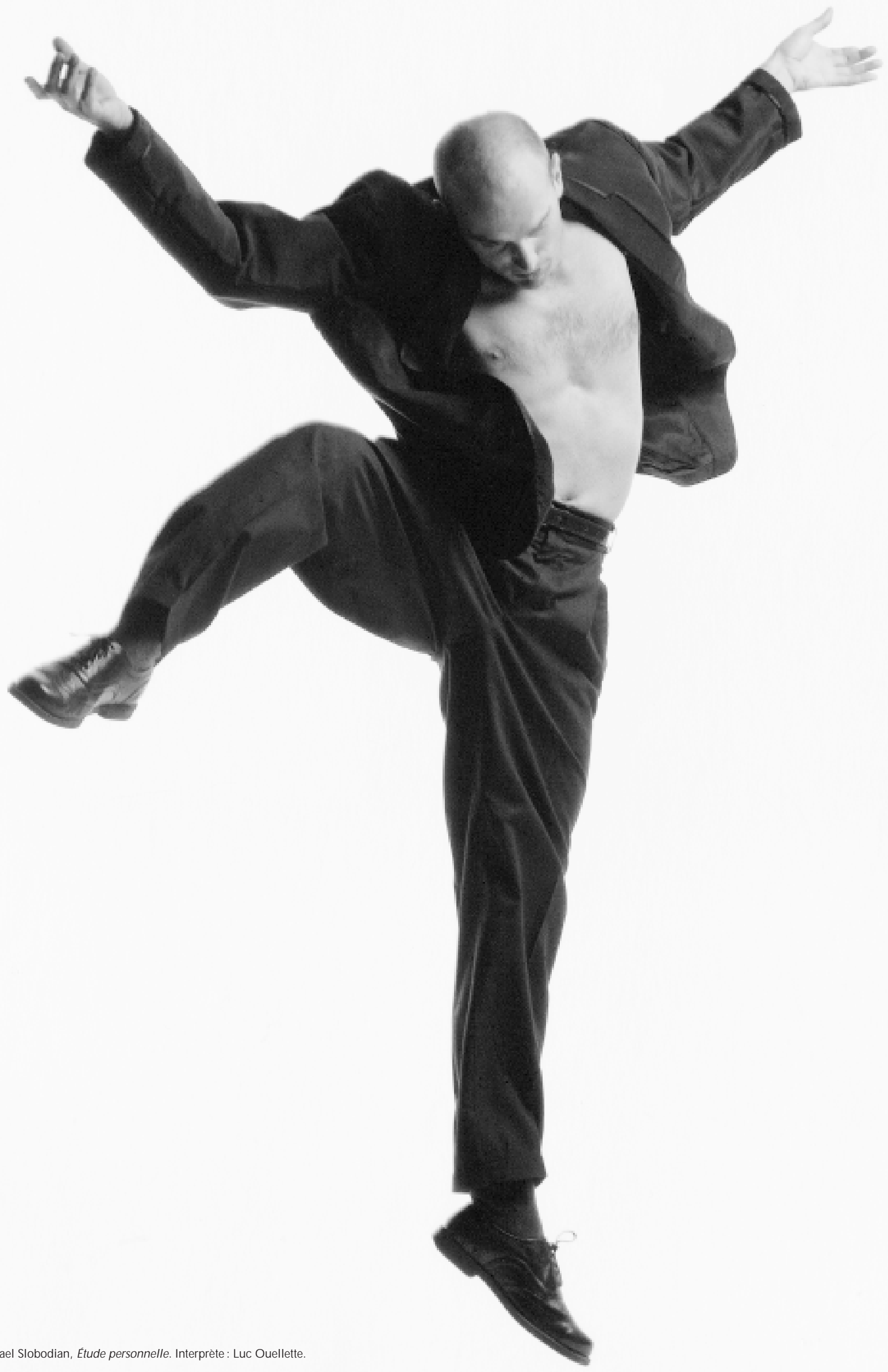


